\title{
Insulin degludec as an ultralong-acting basal insulin once a day: a systematic review
}

This article was published in the following Dove Press journal:

Diabetes, Metabolic Syndrome and Obesity:Targets and Therapy

7 July 2012

Number of times this article has been viewed

\author{
Fei Wang' \\ Justine Surh' \\ Manmeet Kaur ${ }^{2}$ \\ 'University of Connecticut School \\ of Pharmacy, Department of Pharmacy \\ Practice, Storrs, ${ }^{2}$ Joslin Diabetes \\ Center Affiliate, Hospital of Central \\ Connecticut, New Britain, CT, USA
}

Correspondence: Fei Wang University of Connecticut School of Pharmacy, Department of Pharmacy Practice, 69 North Eagleville Road, Unit 3092, Storrs, CT 06269, USA Tel +l 8605454125

$\mathrm{Fax}+\mathrm{I} 8604864733$

Email fei.wang@uconn.edu
Background: Insulin degludec (IDeg) is a neutral, ultralong-acting new generation basal insulin analog developed by NovoNordisk currently in Phase III clinical development. IDeg offers a duration of action of more than 42 hours in adults, much longer than current basal insulin formulations.

Objective: The aim of this review is to assess the efficacy and safety data of IDeg in the treatment of type 1 and type 2 diabetes mellitus.

Methods: Relevant English language articles from 2010 to 2012 were identified through MEDLINE, PubMed, EMBASE, Scopus, BIOSIS, and Google Scholar. Online conference proceedings of the 71st ADA Scientific Sessions and the 47th EASD Annual Meeting were reviewed. Studies were compared in terms of their study designs, primary and secondary efficacy parameters, and tolerability data.

Results: There are a total of nine published trials investigating the clinical efficacy and safety of IDeg in over 3000 subjects with type 1 and 2 diabetes. Only three trials were published in full. All were open-label, randomized multicenter trials with durations of 16 to 52 weeks. IDeg and coformulations of IDeg with insulin aspart (IAsp) were compared to insulin glargine (IGlar), detemir, and biphasic IAsp 30 (BIAsp 30).

Conclusion: Based upon the available evidence, there appear to be no reported differences between IDeg and IGlar, detemir, or BIAsp 30 in the reduction of the primary efficacy end-points of $\mathrm{HbA}_{1 \mathrm{c}}$ and mean fasting plasma glucose (FPG) concentrations. Only flexible dosing of IDeg provided a significant reduction in FPG compared to IGlar. IDeg demonstrated a significant reduction in nocturnal hypoglycemia in type 1 diabetes. In type 2 diabetes, IDeg reduced the incidence of hypoglycemia by $18 \%$ and $58 \%$ compared to IGlar and BIAsp 30, respectively.

Keywords: basal insulin analog/analogue, degludec, degludec/aspart, IDeg, IDegAsp, NN1250, efficacy, safety, comparative study

\section{Introduction}

Insulin analogs are artificially modified insulin molecules that allow better mimicking of endogenous insulin availability and therefore better metabolic control of diabetes. The aim of basal insulin analogues is to provide glycemic control while reducing the risk of hypoglycemia compared with insulin neutral protamine Hagedorn (NPH) by providing a consistent absorption of insulin and a reduced insulin peak. ${ }^{1}$ The two long-acting basal insulin analogs, glargine (IGlar) and detemir, represent clinically relevant advances over NPH insulin in optimizing basal insulin substitution, thus allowing tighter blood glucose control and lowering the risk of hypoglycemia and nocturnal hypoglycemia, ${ }^{2-4}$ while producing similar or lower fasting plasma glucose 
and reducing day-to-day glucose variability. ${ }^{5-7}$ Furthermore, insulin detemir has been consistently associated with less weight gain than with either $\mathrm{NPH}^{3,4,8,9}$ or IGlar. ${ }^{10-12}$ In fact, in one study the weight that was gained with insulin detemir appeared to occur predominantly in the leanest subjects, while those with the largest BMI actually lost weight. ${ }^{13}$

Findings obtained from glucose clamp studies clearly indicate that the two long-acting analogs differ in both their pharmacokinetic (PK) and pharmacodynamic (PD) profiles, with both analogs having a longer duration of insulin effect and smoother action profile compared with NPH. ${ }^{14} \mathrm{~A}$ recent systematic review of randomized, controlled trials with a duration of 12 weeks or longer that compared insulin detemir to IGlar in people with type 2 diabetes suggests that these two treatments offer similar glycemic control with no clinically relevant difference in efficacy or safety. However, to achieve the same glycemic control, insulin detemir was often injected twice daily in a higher dose, while IGlar was injected once daily; insulin detemir resulted in less weight gain, while IGlar was associated with somewhat fewer injection site reactions. ${ }^{15}$ Although IGlar is commonly used twice daily in practice, comparative studies have almost exclusively been confined to once daily injection in accordance with its license. This is in contrast to insulin detemir, which has been used both once and twice daily.

\section{Insulin degludec}

Insulin degludec (IDeg) is a neutral ultralong-acting new generation basal insulin analog that was developed by NovoNordisk (Bagsvaerd, Denmark) and which is currently in Phase III clinical development. IDeg offers a much longer duration of action than current basal insulin formulations, with a duration of action of more than 42 hours in adults. ${ }^{16}$ It has the potential to broaden the options for current diabetes treatment with a flexible thrice weekly ${ }^{17}$ dosing regimen that can be administered at any time of the day. ${ }^{18-20}$ These characteristics will facilitate the integration of insulin therapy with daily activities and potentially improve adherence and acceptance of basal insulin treatment. Furthermore, in patients with type 1 diabetes, IDeg also improved psychological well-being and quality of life. ${ }^{21}$

The IDeg molecule retains the human insulin amino acid sequence except for the deletion of threonine in the B30 position (ThrB30) and the addition of a 16-carbon fatty diacid side chain attached to lysine in position B29 (LysB29) of the insulin B-chain via a glutamic acid linker. ${ }^{22,23}$ IDeg exists in a dihexameric state when in solution prior to administration. ${ }^{24}$ This structural modification is designed to allow IDeg to self-associate to form large multihexamer assemblies at the site of injection following subcutaneous administration, as the additives (phenol, m-cresol, and zinc) in the formulation disperse. ${ }^{24}$ Its ultralong effect is primarily a result of the slow release of IDeg monomers from soluble multihexamers, resulting in a depot from which IDeg is continuously and slowly absorbed into the circulation. ${ }^{16,22,25}$ This mechanism of action gives rise to an ultralong and flat action profile at steady state when administered to people with type 1 and type 2 diabetes.

The efficacy and safety of IDeg has been compared to IGlar ${ }^{17-20,26-35}$ and insulin detemir. ${ }^{36}$ In these studies, IDeg demonstrated comparable glycemic control, ${ }^{17-20,26,28-34,36-38}$ with lower rates of hypoglycemia ${ }^{29,30,32,33,37,39}$ and nocturnal hypoglycemia, ${ }^{26,28,32,33,36}$ suggesting a better tolerability profile as a result of improved pharmacokinetics. ${ }^{34}$

IDeg is a clear solution of $\mathrm{pH} 7.4$ with a $\mathrm{pH}$-dependent solubility and an isoelectric point similar to that of human insulin. It is to be administered subcutaneously. As is the case for human insulin, each unit of IDeg solution contains 6 nmol of IDeg. ${ }^{24}$ IDeg is also being developed in a soluble coformulation with rapid acting insulin aspart (IAsp), which is referred to as IDegAsp or Degludec Plus. A sizeexclusion chromatography of the coformulation product identified the formation of multihexamers composed distinctly of degludec under physiological conditions providing the basal insulin coverage, while rapid-acting IAsp was predominantly present as monomers, allowing fast absorption into the bloodstream. ${ }^{40}$ IDegAsp is a soluble formulation of basal insulin analog IDeg (70\%) and IAsp (30\%) and has been evaluated in a number of studies. ${ }^{31,36-38,41}$ An alternate formulation of 55\% IDeg and $45 \%$ IAsp has also been studied. ${ }^{38}$ Two different formulations of IDeg insulin have also been compared: $100 \mathrm{U} / \mathrm{mL}$ (U-100) and $200 \mathrm{U} / \mathrm{mL}$ (U-200). The U-200 formulation of IDeg is twice as concentrated as traditional U-100 insulin formulations. Both of these formulations demonstrated bioequivalence and similar pharmacodynamic profiles at steady state without any marked differences in adverse or hypoglycemic events. ${ }^{42}$ The availability of a U-200 formulation in clinical practice has the potential to enable higher doses to be administered in a given injection volume.

\section{Pharmacokinetics and pharmacodynamics}

The PK and PD characteristics of IDeg have been studied in subjects with type $1^{16,22,23,35,42-45}$ and type 2 diabetes. ${ }^{25}$ 
These data are available only in abstract form as they were presented at conference proceedings. Multiple abstracts were published in both the 2011 American Diabetes Association (ADA) and European Association for the Studies of Diabetes (EASD) conference proceedings. ${ }^{16,22,23,25,42}$ A small unpublished study investigating the PK properties of IDeg in healthy subjects was completed at the end of $2011 .{ }^{46}$

The PK and PD of IDeg in type 1 diabetes has been evaluated in eight small studies $(n=12-66)^{16,22,23,35,42-45}$ and has been compared to IGlar (Sanofi-SA, Paris, France). ${ }^{35,43-45}$ The PK and PD of IDeg has been assessed in only one study $(n=49)$ of people with type 2 diabetes. ${ }^{25}$ All of these studies used the euglycemic glucose clamp technique to measure PD profiles and within-subject variability estimated on log-transformed pharmacodynamic end-points derived from the glucose infusion rate profiles during the clamps. However, in the majority of studies, the method of glucose clamping (ie, manual versus using an automated "artificial pancreas") was not revealed, so it is not possible to compare the data. ${ }^{14}$ Overall, information from these studies demonstrates that when IDeg is administered once daily under steady-state conditions it is significantly less variable within subjects and more stable in glucose-lowering effect than IGlar.

\section{Type I diabetes}

Evidence of a prolonged action profile of IDeg was first provided in a study by Jonassen et al in twelve subjects with type 1 diabetes. ${ }^{22,23}$ Following 6 days of subcutaneous injection with IDeg $(5.0 \mathrm{nmol} / \mathrm{kg}$, once daily), the mean steady state PK profile demonstrated a smooth and stable exposure over 24 hours. IDeg was found to have a $t_{1 / 2}$ longer than 24 hours and was detectable in the circulation for at least 96 hours after the final injection, although it cannot be concluded from this that IDeg would still be biologically active at that time.

This information was confirmed in a 42-hour euglycemic clamp study of therapeutic doses of IDeg $(0.4,0.6$, or $0.8 \mathrm{U} / \mathrm{kg}$ ) administered subcutaneously once daily to 21 subjects. After 8 days, the steady state glucose-lowering effect of IDeg extended beyond 42 hours at all three doses. End of action (blood glucose $(\mathrm{BG})>150 \mathrm{mg} / \mathrm{dL}$ ) did not occur within the 42-hour clamp period for any subjects dosed with 0.6 or $0.8 \mathrm{U} / \mathrm{kg}$ IDeg and only for three of the 21 subjects on $0.4 \mathrm{U} / \mathrm{kg}$ IDeg. Moreover, mean blood glucose profiles measured over the 4-hour clamp remained almost horizontal for the 0.6 or $0.8 \mathrm{U} / \mathrm{kg}$ dose groups, showing that blood glucose was controlled throughout the 42-hour period. ${ }^{16}$
The PK properties of IDeg also appeared to be preserved in children and adolescents with type 1 diabetes $(n=25)$ after a single $(0.4 \mathrm{U} / \mathrm{kg})$ dose of IDeg insulin. IDeg was detected 72 hours after administration for all subjects. Total exposure to IDeg (AUC) tended to be greater in children and adolescents than in adults, with no differences in maximum IDeg concentration $\left(\mathrm{C}_{\max }\right){ }^{45}$

\section{Comparison with insulin glargine}

The PK properties of IDeg were compared to those of IGlar under steady state conditions in two studies in people with type 1 diabetes. ${ }^{35,43}$

In a randomized, double-blind, two-period crossover trial, 66 people with type 1 diabetes (55 males and 11 females, mean age $=37$ years, glycosylated hemoglobin $\left[\mathrm{HbA}_{1 \mathrm{c}}\right]$ 8.1\%, body mass index [BMI] $24.9 \mathrm{~kg} / \mathrm{m}^{2}$ ) received one of three fixed doses $(0.4,0.6$, or $0.8 \mathrm{U} / \mathrm{kg})$ of IDeg and IGlar once daily for 8 days with 7-21 days of wash-out between treatments. ${ }^{43}$ A euglycemic glucose clamp was performed on treatment day 8 , and $\mathrm{PK}$ samples were taken throughout each treatment period and for 120 hours after the last dose. IDeg showed stable PK concentrations under steady-state conditions, and demonstrated minimal fluctuations that increased proportionally with increasing dose. The serum exposure to IDeg was equally distributed between the first and the second 12-hour period post-dosing, whereas IGlar showed a higher exposure during the first 12 hours. Likewise, the cumulated AUC below and above the average glucose infusion rate was considerably lower for all doses of IDeg $(0.25,0.37$, and $0.38 \mathrm{mg} / \mathrm{kg} / \mathrm{minute})$ than with IGlar $(0.39,0.54$, and $0.73 \mathrm{mg} / \mathrm{kg} / \mathrm{minute})$. IDeg was detectable in the serum for at least 120 hours following the final dose, whereas IGlar fell below the lower limit of quantification 36-48 hours post-dosing for most subjects. Mean terminal half-life was twice as long for IDeg than IGlar (25.4 vs 12.5 hours). Both insulin preparations were well tolerated and no safety concerns were identified. This study concluded that IDeg has a half-life that is twice as long as that of IGlar, resulting in a more evenly distributed and stable PK profile, and a more stable and less variable glucose lowering effect than IGlar.

In a parallel group, randomized double-blind study, 54 people with type 1 diabetes (48 males and six females, mean age $=38 \pm 10$ years, mean $\mathrm{HbA}_{1 \mathrm{c}}=7.7 \% \pm 0.9 \%$, mean $\mathrm{BMI}=24.6 \pm 2.2 \mathrm{~kg} / \mathrm{m}^{2}$ ) were treated with $0.4 \mathrm{U} / \mathrm{kg}$ IDeg or IGlar once daily for 12 days. ${ }^{35}$ On treatment days 6 , 9 , and 12, pharmacodynamic profiles were investigated over 
24 hours with the glucose clamp technique (Biostator; Miles Laboratories, Elkhart, IN). IDeg produced significantly less pharmacodynamic variability than IGlar on all protocol pharmacodynamic variability parameters, including total metabolic effect $(P<0.0001)$. The individual withinsubject variability was consistently lower for IDeg compared with IGlar $(P<0.001)$. IDeg's metabolic effect was evenly distributed between the first and the second 12 hours, and this distribution was less variable than that seen with IGlar $(P<0.001)$. Both insulin types were well tolerated, without serious adverse events and without severe hypoglycemic episodes. This study demonstrated that once daily administration of IDeg is significantly less variable and more stable in glucose lowering effect than IGlar. A post-hoc analysis confirmed that the lower within-subject variability of IDeg was consistent over time, whereas the variability of IGlar was higher and increased substantially after 8 hours post-dosing. ${ }^{44}$ In conclusion, the within-subject variability for IDeg is consistently and significantly (4 times) lower than IGlar over 24 hours, which may be due to the slow release of IDeg monomers from soluble multihexamers that form after subcutaneous injection. IDeg's lower within-subject variability is thought to contribute to the lower risk of hypoglycemia observed in clinical studies.

\section{Type 2 diabetes}

A double-blind, two-period crossover trial investigated the dose-response relationship of three doses of IDeg $(0.4,0.6$, and $0.8 \mathrm{U} / \mathrm{kg})$ at steady state in 49 people with type 2 diabetes who were insulin-treated without concomitant oral antidiabetic agents (OADs). ${ }^{25}$ Participants (mean age $=58.7$ years, mean $\mathrm{HbA}_{1 \mathrm{c}}=7.6 \%$, mean $\mathrm{BMI}=29.6 \mathrm{~kg} / \mathrm{m}^{2}$, mean duration of diabetes $=14.1$ years $)$ were given IDeg once-daily for 6 days, with a washout period of 13 to 21 days between treatments. Following dosing on day 6 , subjects underwent a euglycemic glucose clamp study. PK samples were taken up to 120 hours after the last injection of IDeg. For all dose levels, mean 24 hour glucose infusion rate (GIR) profiles were flat and stable. The total glucose-lowering effect of IDeg increased linearly with increasing dose. The terminal half-life estimated across the three dose levels after the last dose was 25.1 hours. IDeg was well tolerated and no safety concerns were identified. In summary, it is noteworthy that in all of these PK and PD glucose clamp studies, IDeg insulin at steady state demonstrated a flat action profile with a prolonged duration of action beyond 24 hours, a more stable blood glucose- lowering effect, and lower within-subject variability in subjects with both type 1 and type 2 diabetes. This data seems to support the once daily or three times a week administration of IDeg. ${ }^{17,34}$

\section{Clinical trials}

All of the clinical trials summarized in Tables 1 and 2 were open-label phase II and III studies of IDeg sponsored by NovoNordisk. The primary efficacy endpoint was $\mathrm{HbA}_{1 \mathrm{c}}$ levels from baseline to end of study. Secondary efficacy endpoints were changes in FPG. Tolerability and safety variables in most trials included confirmed hypoglycemic and nocturnal hypoglycemic episodes, adverse events including injection-site reactions, and changes in body weight from baseline.

At the time of writing, there are three trials investigating the clinical efficacy and safety of IDeg in subjects with type 1 diabetes. One Phase II study was presented in full ${ }^{29}$ and in abstracts, ${ }^{30,47}$ and two Phase III studies were presented in abstract form at conference proceedings of the 2011 ADA $^{28,37}$ and the EASD. ${ }^{26,36}$ Home et $\mathrm{al}^{48}$ reported an improved quality of life with IDeg compared to IGlar using data from the Phase II study. ${ }^{29}$ Both IGlar and insulin detemir are used as comparators, mostly in combination with IAsp. Table 1 shows a summary of these trials.

In type 2 diabetes, there are a total of six trials investigating the clinical efficacy and safety of IDeg. Two Phase II studies are available in full ${ }^{34,38}$ (parts of these studies are also presented in abstract form $)^{17,31}$ and four studies (Phase II and III) are available only in abstract form ${ }^{18,20,32,33,41,49-51}$ and presented at multiple conference proceedings: ADA, ${ }^{18,33,41}$ EASD, ${ }^{19,20,32,49}$ and International Diabetes Federation. ${ }^{50,51}$ Table 2 shows a summary of these trials.

At the time of writing, there are several ongoing Phase III clinical trials in type 2 diabetes comparing the dual action of IDeg and liraglutide to IDeg alone, switching from IGlar to IDeg (BEGINTM), comparing two IDeg formulations, and comparing the efficacy and safety of two intensification strategies in subjects with type 2 diabetes inadequately controlled on basal insulin and metformin. ${ }^{52}$

\section{Degludec in type I diabetes}

The clinical efficacy, safety, and tolerability of IDeg in subjects with type 1 diabetes were all assessed during short-term open-label trials with a duration of 16 weeks, ${ }^{29}$ 26 weeks, ${ }^{36,37}$ and 52 weeks. ${ }^{26,28}$ Only one study published in full demonstrated adequate power. ${ }^{29}$ 


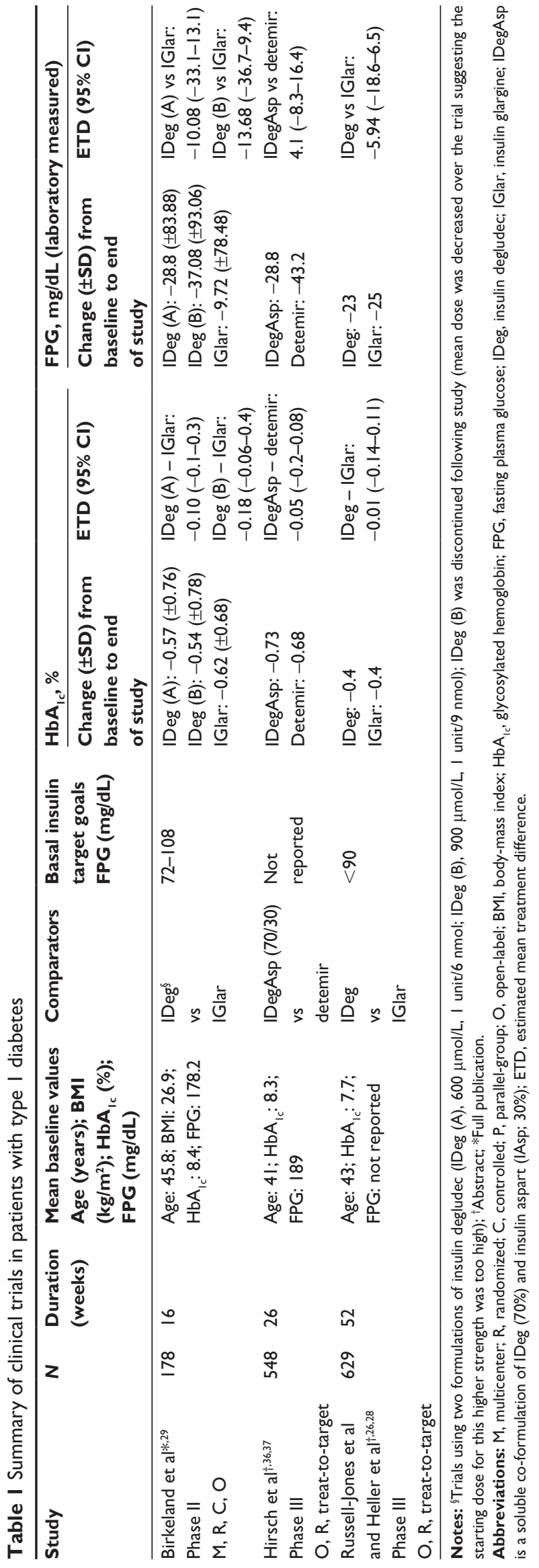

\section{Comparative studies with insulin glargine}

Phase II

In a 16 -week, ${ }^{29}$ multicenter, open-label three-arm parallelgroup trial, 178 participants with type 1 diabetes (mean age $=45.8$ years, , mean $\mathrm{HbA}_{1 \mathrm{c}}=8.4 \%$, mean $\mathrm{FPG}=178 \mathrm{mg} / \mathrm{dL}$ $(9.9 \mathrm{mmol} / \mathrm{L})$, mean BMI $\left.=26.9 \mathrm{~kg} / \mathrm{m}^{2}\right)$ received subcutaneous injections of IDeg (A) $(600 \mu \mathrm{mol} / \mathrm{L}, 1$ unit $/ 6 \mathrm{nmol}$, $n=59)$, IDeg (B) $(900 \mu \mathrm{mol} / \mathrm{L}, 1$ unit $/ 9 \mathrm{nmol}, n=60)$, or IGlar $(n=59)$, all given once daily in the evening. IAsp was administered as mealtime insulin. Basal insulin was titrated to a FPG target of $72-108 \mathrm{mg} / \mathrm{dL}(4.0-6.0 \mathrm{mmol} / \mathrm{L})$. After 16 weeks, mean $\mathrm{HbA}_{1 \mathrm{c}}$ was comparable for IDeg (A) $(7.8 \% \pm 0.8 \%)$, IDeg (B) $(8.0 \% \pm 1.0 \%)$, and IGlar $(7.6 \% \pm 0.8 \%)$. The estimated mean rates of hypoglycemia were $28 \%$ lower for IDeg (A) compared with IGlar (relative risk $[\mathrm{RR}]=0.72,95 \%$ confidence interval $[\mathrm{CI}]: 0.52-1.00$ ) and $10 \%$ lower for IDeg (B) compared with IGlar $(\mathrm{RR}=0.90$, 95\% CI: 0.65-1.24). Rates of nocturnal hypoglycemia were $58 \%$ lower for IDeg (A) (RR $=0.42,95 \% \mathrm{CI}$ : $0.25-0.69)$ and $29 \%$ lower for IDeg (B) $(\mathrm{RR}=0.71,95 \% \mathrm{CI}$ : 0.44-1.16). Mean total daily insulin dose was similar to baseline. Mean body weight change after 16 weeks was $+0.1 \pm 2.7 \mathrm{~kg}$ for IDeg (A), $+1.0 \pm 2.5 \mathrm{~kg}$ for IDeg (B), and $+0.7 \pm 1.6 \mathrm{~kg}$ for IGlar. The frequency and pattern of adverse events was similar between insulin treatments.

\section{Phase III}

In another 52-week, open-label, treat-to-target trial with 629 adults with type 1 diabetes (mean age $=43.0$ years, mean diabetes duration $=18.9$ years, mean $\mathrm{HbA}_{1 \mathrm{c}}=7.7$ ) were randomized in a 3:1 ratio to receive either IDeg or IGlar, and the basal insulin was titrated aiming for a FPG target $<90 \mathrm{mg} / \mathrm{dL}$ $(5 \mathrm{mmol} / \mathrm{L}) .{ }^{26,28} \mathrm{IAsp}$ was administered as background mealtime insulin. By the end of the trial, overall glycemic control improved by $0.4 \%$ points with both IDeg and IGlar (estimated treatment difference [ETD] IDeg-IGlar $=-0.01 \%$ points [95\% CI: -0.14-0.11]). Mean FPG was reduced by $23 \mathrm{mg} / \mathrm{dL}$ $(1.27 \mathrm{mmol} / \mathrm{L})$ and $25.0 \mathrm{mg} / \mathrm{dL}(1.39 \mathrm{mmol} / \mathrm{L})$ for IDeg and IGlar, respectively $(\mathrm{ETD}=-5.9 \mathrm{mg} / \mathrm{dL}[-0.33 \mathrm{mmol}], 95 \%$ CI: $-18.6-6.5 ; P=\mathrm{NS}$ ). The first time to meet titration target was shorter with IDeg (median of 5 vs 10 weeks, estimated hazard ratio $=1.37,95 \%$ CI: $1.12-1.67 ; P=0.002$ ). Rates of overall confirmed hypoglycemia were similar for IDeg and IGlar (42.5 vs 40.2 episodes/patient year, estimated rate ratio $[$ ERR] $=1.07,95 \% \mathrm{CI}: 0.89-1.28 ; P=\mathrm{NS}$ ). Rates of nocturnal hypoglycemia were $25 \%$ lower with 


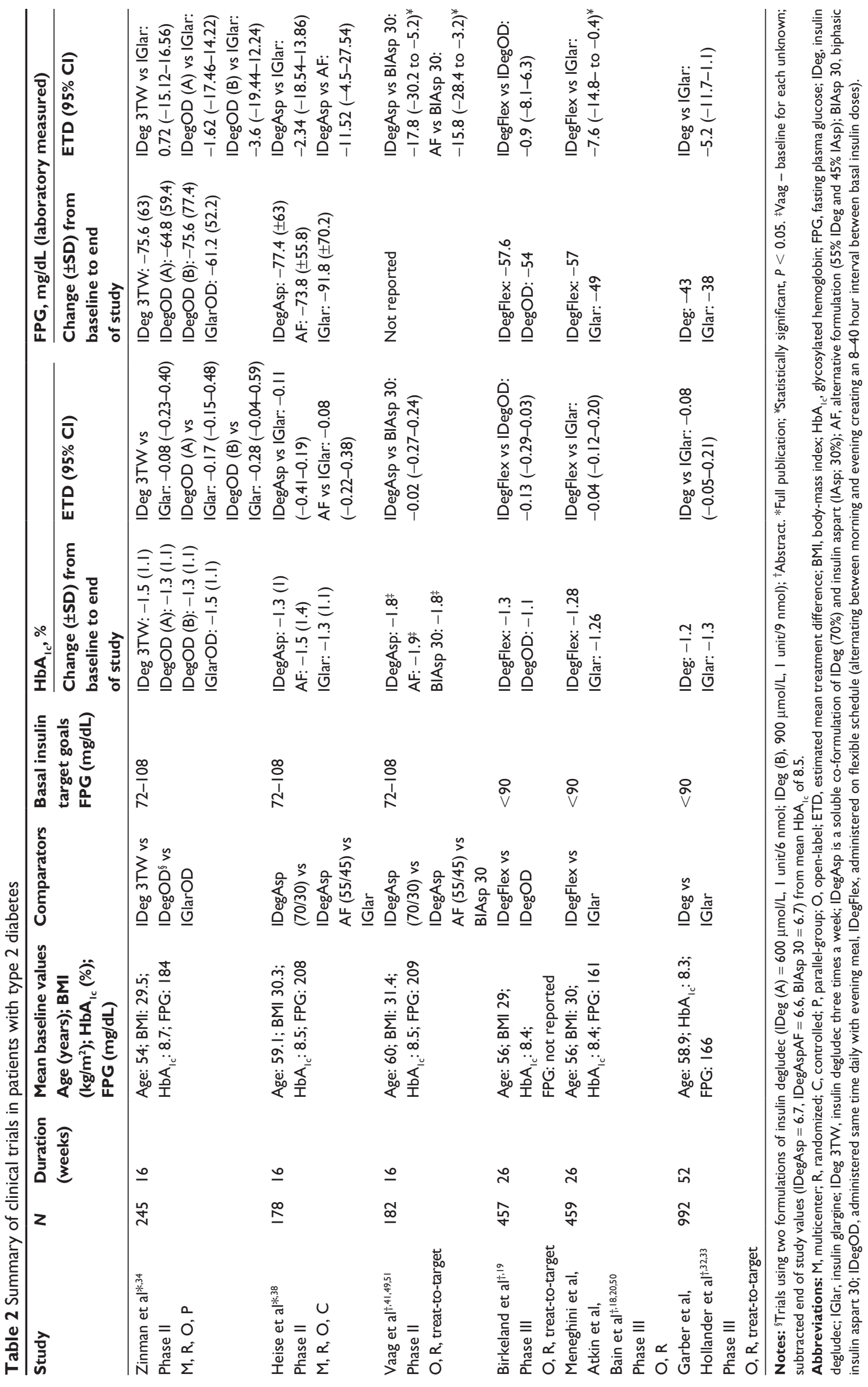


IDeg (4.4 vs 5.9 episodes/patient year, ERR $=0.75,95 \%$ CI: $0.59-0.96 ; P=0.021)$. Mean total daily insulin dose was similar to baseline. Overall rates of adverse events were similar between groups.

\section{Comparative study with insulin detemir}

A Phase III, 26-week, open-label treat-to-target trial compared the efficacy and safety of IDeg/IAsp (IDegAsp), a coformulation of IDeg (70\%) and IAsp (30\%) versus basal insulin detemir (IDet). ${ }^{36,37} 548$ people with type 1 diabetes (mean age $=41$ years, $\mathrm{HbA}_{1 \mathrm{c}}=8.3 \%, \mathrm{FPG}=189 \mathrm{mg} / \mathrm{dL}$ [10.5 $\mathrm{mmol} / \mathrm{L}])$ were randomized $2: 1$ to receive IDeg/Asp or detemir treatment once a day. IAsp was administered as background mealtime insulin. Similar proportions of participants completed the trial (87\% for IDeg/Asp vs $86 \%$ for detemir). By the end of the trial, overall glycemic control was similar in both groups $(0.73 \%$ point reduction for IDeg/Asp vs $0.68 \%$ point reduction for detemir, ETD IDegAsp-detemir $=-0.05 \%$ point, $95 \%$ CI: $-0.18-0.08$; $P=\mathrm{NS})$. FPG was reduced by $29 \mathrm{mg} / \mathrm{dL}(1.6 \mathrm{mmol} / \mathrm{L})$ with IDegAsp and by $43.2 \mathrm{mg} / \mathrm{dL}(2.4 \mathrm{mmol} / \mathrm{L})$ with detemir $($ ETD IDegAsp-detemir $=4.14 \mathrm{mg} / \mathrm{dL}[0.23 \mathrm{mmol} / \mathrm{L}], 95 \%$ CI: $-0.46-0.91 ; P=0.52)$. Confirmed hypoglycemia was similar in both groups (39 vs 44 episodes/patient-year, ERR IDegAsp/IDet $=0.91,95 \%$ CI: $0.76-1.09 ; P=0.27$ ). The rate of nocturnal confirmed hypoglycemia was $37 \%$ lower with IDegAsp (3.7 vs 5.7 episodes/patient-year, ERR $=0.63,95 \%$ CI: $0.49-0.81 ; P=0.0003)$. Mean total insulin daily doses were similar in both groups by the end of the study $(0.86 \mathrm{U} / \mathrm{kg}$ vs $1.00 \mathrm{U} / \mathrm{kg}$ for IDegAsp and detemir groups, respectively). After 26 weeks, mean body weight had increased by $2.4 \mathrm{~kg}$ and $1.4 \mathrm{~kg}$, respectively (ETD IDegAsp-detemir $=1.0 \mathrm{~kg}$, 95\% CI: $0.38-1.69 ; P=0.0021)$. Overall, rates for adverse events were similar between groups.

\section{Degludec in type 2 diabetes}

Four of these studies compared IDeg and/or different coformulations of IDeg (IDegAsp) to IGlar. ${ }^{18-20,32-34,38,50}$ One study compared IDeg to biphasic IAsp 30 (BIAsp 30), ${ }^{41,49,51}$ and one study compared flexible dosing versus once daily dosing of IDeg. ${ }^{19}$

\section{Phase II trials \\ Comparison with insulin glargine}

In a 16-week, open-label, randomized, four-arm, parallelgroup, treat-to-target trial, insulin-naïve participants (mean age $=54.2$ years, mean $\mathrm{HbA}_{1 \mathrm{c}}=8.7 \%$, mean $\mathrm{FPG}=184 \mathrm{mg} / \mathrm{dL}$
[10.2 $\mathrm{mmol} / \mathrm{L}]$, mean $\mathrm{BMI}=29.5 \mathrm{~kg} / \mathrm{m}^{2}$ ) received a once a day formulation of IDeg $(600 \mathrm{nmol} / \mathrm{mL}$ formulation, starting dose $10 \mathrm{U}[1 \mathrm{U}=6 \mathrm{nmol}]$ ) (IDegOD, group $\mathrm{A}, n=60$ ), a three times a week formulation of IDeg $(900 \mathrm{nmol} / \mathrm{mL}$ formulation, starting dose $20 \mathrm{U}[1 \mathrm{U}=9 \mathrm{nmoL}]$ ) (IDeg $3 \mathrm{TW}$, group $\mathrm{B}, n=62$ ), an alternative once a day IDeg formulation $(900 \mathrm{mmol} / \mathrm{mL}$ formulation, starting dose $10 \mathrm{U}[1 \mathrm{U}=9 \mathrm{nmol}])(n=61)$, or IGlar daily (starting dose $10 \mathrm{U}[1 \mathrm{U}=6 \mathrm{nmol}]$ ) (IGlarOD, $n=62$ ), all in combination with metformin. ${ }^{34}$ All insulin was injected subcutaneously in the evening and titrated to achieve FPG $72-108 \mathrm{mg} / \mathrm{dL}$ (4.0-6.0 $\mathrm{mmol} / \mathrm{L})$.

At the end of the study period, $\mathrm{HbA}_{1 \mathrm{c}}$ was similar across treatment arms with regard to mean reduction from baseline (IDegOD [groups A and B] $=-1.3 \%$, IDeg $3 \mathrm{TW}=-1.5 \%$, IGlarOD $=-1.50 ; P=\mathrm{NS})$. Estimated mean $\mathrm{HbA}_{1 \mathrm{c}}$ treatment differences from IDeg in comparison with IGlar were $0.08 \%$ (95\% CI: $-0.23-0.40$ for IDeg 3TW schedule, 0.17\% (95\% CI: $-0.15-0.48)$ for group A, and $0.28 \%$ (95\% CI: - 0.04-0.59) for group B. Treatments were also comparable with respect to final mean reductions in FPG from baseline (IDegOD group $\mathrm{A}=-64.8 \mathrm{mg} / \mathrm{dL}$, IDegOD group $\mathrm{B}=-75.6 \mathrm{mg} / \mathrm{dL}$, IDeg $3 \mathrm{TW}=-75.6 \mathrm{mg} / \mathrm{dL}$, IGlarOD $=-61.2 \mathrm{mg} / \mathrm{dL}$ ). At the end of the trial, mean weekly insulin dose were similar and mean body weight remained constant throughout the trial in all treatment arms. Overall rates of confirmed hypoglycemia (defined as $<56 \mathrm{mg} / \mathrm{dL}$ ) were low in all treatment groups, with $77 \%-92 \%$ of participants not reported to have had a hypoglycemic episode. Estimated odds ratios of confirmed hypoglycemic episodes by comparison with IGlar were IDeg $3 \mathrm{TW}=84$ (95\% CI: $0.35-2.03 ; P=\mathrm{NS})$, IDeg group $\mathrm{A}=0.26$ (95\% CI: $0.08-0.81 ; P<0.05$ ), and IDeg group $\mathrm{B}=0.57$ (95\% CI: $0.22-1.49 ; P=\mathrm{NS}$ ). The proportion of participants who had hypoglycemia in IDeg group A was lower than the proportion in the IGlar group and the IDeg three times a week group. The rate of confirmed nocturnal hypoglycemia was low and similar in all treatment groups. Body weight was stable throughout the trial in every group. A significant difference was noted between the IDeg group B and IGlar groups $(1.00,95 \% \mathrm{CI}$ : $0.17-1.83 ; P<0.05)$. Overall rates of adverse effects of mild-to-moderate severity (headache, dermatitis, pruritic rash, diarrhea, stomach discomfort, and peripheral edema) were reported by $10 \%$ of participants in the IDeg three times a week group. There were few injection site reactions reported.

In another proof-of-concept trial, IDegAsp was compared to IGlar in a 16-week, multicenter, open-label, randomized, parallel-group, treat-to-target trial of insulin-naïve people 
with type 2 diabetes who were inadequately controlled on oral antidiabetic drugs. ${ }^{38}$ Subjects (mean age $=59.1$ years, mean $\mathrm{HbA}_{1 \mathrm{c}}=8.5 \%$, mean $\mathrm{BMI}=30.3 \mathrm{~kg} / \mathrm{m}^{2}$ ) were randomized to once daily IDegAsp (IDeg [70\%] and IAsp [30\%, $n=59]$ ), an alternative formulation (AF) of IDegAsp (AF $=55 \%$ IDeg and $45 \%$ IAsp, $n=59)$, or IGlar $(n=60)$, all in combination with metformin for 16 weeks. The insulin starting dose was 10 units administered in the abdomen (IDegAsp, AF) or thigh (IGlar). Insulin was dosed subcutaneously before dinner and titrated to a FPG target of 72-108 mg/dL (4.0-6.0 mmol/L).

After 16 weeks, mean $\mathrm{HbA}_{1 \mathrm{c}}$, decreased from baseline in all treatment groups (IDegAsp $=-1.31 \%, \mathrm{AF}=-1.46 \%$, IGlar $=-1.29 \%)$ to comparable end of trial values $(7.0 \%, 7.2 \%$, and $7.1 \%$, respectively, $P=$ NS for all pairwise comparisons). IDegAsp was associated with a $0.11 \%$ point greater reduction in $\mathrm{HbA}_{1 \mathrm{c}}$ compared with IGlar (estimated mean treatment difference $=-0.11,95 \%$ CI: $-0.41-0.19)$, and a $0.08 \%$-point greater reduction in $\mathrm{HbA}_{1 \mathrm{c}}$ compared with AF (estimated mean treatment difference AF-IDegAsp =0.08, 95\% CI: $-0.22-0.38$ ). Mean reductions in FPG values were similar across treatment groups $($ IDegAsp $=122 \mathrm{mg} / \mathrm{dL}[6.8 \mathrm{mmol} / \mathrm{L}], \mathrm{AF}=133 \mathrm{mg} / \mathrm{dL}$ $[7.4 \mathrm{mmol} / \mathrm{L}]$, IGlar $=126 \mathrm{mg} / \mathrm{dL}[7.0 \mathrm{mmol} / \mathrm{L}])$. IDegAsp was associated with a $2.34 \mathrm{mg} / \mathrm{dL}(0.13 \mathrm{mmol} / \mathrm{L})$ greater reduction compared with IGlar (estimated mean treatment difference [IDegAsp-IGlar] =-2.34 mg/dL, 95\% CI: 18.54-13.86) and a $11.52 \mathrm{mg} / \mathrm{dL}(0.64 \mathrm{mmol} / \mathrm{L})$ greater reduction in FPG compared with AF (estimated mean treatment difference $($ AF-IDegAsp $)=11.52 \mathrm{mg} / \mathrm{dL}(95 \% \mathrm{CI}:$-4.5-27.54)) Mean self-measured 2-hour postdinner postprandial plasma glucose $(P G)$ increments (plasma glucose concentration 2 hours after a meal minus the plasma glucose concentration measured immediately prior to the meal) were similar for all treatments after breakfast and lunch. However, the increase in mean 2-hour postdinner plasma glucose was substantially lower for IDegAsp $(2.34 \mathrm{mg} / \mathrm{dL}$ [0.13 mmol/L]) and $\operatorname{AF}(4.32 \mathrm{mg} / \mathrm{dL}[0.24 \mathrm{mmol} / \mathrm{L}])$ compared with IGlar $(29.34 \mathrm{mg} / \mathrm{dL}[1.63 \mathrm{mmol} / \mathrm{L}])$. The estimated mean treatment difference was $-24.1 \mathrm{mg} / \mathrm{dL}(-1.34 \mathrm{mmol} / \mathrm{L})$ (95\% CI: -44.1 - to -4.1 ) for IDegAsp-IGlar.

No severe hypoglycemic events were reported. Rates of confirmed hypoglycemia (plasma glucose $<56 \mathrm{~mL}$ / minute) were lower for IDegAsp and IGlar than AF (1.2, 0.7, and 2.4 events/patient year). Nocturnal hypoglycemia occurred rarely for IDegAsp (one subject, one event) and IGlar (three subjects, three events), compared with AF (10 subjects, 27 events). At the end of the trial, mean daily insulin doses were approximately $20 \%$ lower for IDegAsp and AF than for IGlar $(0.38 \pm 0.16,0.36 \pm 0.16$, and $0.45 \pm 0.20$ units $/ \mathrm{kg}$, respectively). Changes in mean body weight observed from baseline to week 16 for IDegAsp, AF, and IGlar were $-0.4 \pm 2.3 \mathrm{~kg}, 0.3 \pm 2.2 \mathrm{~kg}$, and $-0.1 \pm 3.2 \mathrm{~kg}$, respectively. Adverse events with a possible or probable relation to insulin were only reported for AF. The authors concluded that IDegAsp provided comparable overall glycemic control to IGlar at similar rates of hypoglycemia, with the additional benefit of postdinner PG control.

\section{Comparison with biphasic insulin aspart 30 (BIAsp 30)}

This 16-week, open-label, treat-to-target trial investigated the efficacy and safety of IDegAsp (IDeg 70\%, IAsp 30\%) in insulin-naïve people with type 2 diabetes that were inadequately controlled on OADs. ${ }^{41,49,51}$ Subjects (mean age $=60$ years, mean $\mathrm{HbA}_{1 \mathrm{c}}=8.5 \%$, mean $\mathrm{FPG}=209 \mathrm{mg} / \mathrm{dL}$ ) were randomized to twice-daily IDegAsp $(n=61)$, BIAsp 30 $(n=62)$, or an alternative formulation of IDegAsp (AF, $n=59)$ with a higher percentage of IAsp (45\%), or BIAsp $30(n=62)$, all in combination with metformin (1500 or $2000 \mathrm{mg} /$ day). Insulin was dosed subcutaneously before breakfast and before the evening meal and titrated to a prebreakfast and predinner PG target of $72-108 \mathrm{mg} / \mathrm{dL}$.

After 16 weeks, mean $\mathrm{HbA}_{1 \mathrm{c}}$ was comparable for IDegAsp, AF, and BIAsp 30 (6.7\%, 6.6\%, and 6.7\%, respectively). Mean FPG was significantly lower for IDegAsp vs BIAsp 30 (treatment difference [TD] $=-17.8 \mathrm{mg} / \mathrm{dL}, 95 \%$ CI: $-30.2-5.2$ ), and AF vs BIAsp 30 (TD $=-15.8 \mathrm{mg} / \mathrm{dL}, 95 \%$ CI: -28.4-3.2). The rate of confirmed hypoglycemia was $58 \%$ lower for IDegAsp than BIAsp 30 (2.9 vs 7.3 episodes/patient year, rate ratio $=0.42[0.23 ; 0.75])$, while rates were similar for BIAsp 30 and AF. Nocturnal confirmed hypoglycemia was less frequent for IDegAsp (7 episodes) than AF (14 episodes) and BIAsp 30 (20 episodes). The overall rate of adverse events was similar between insulins and the majority $(>99 \%)$ were mild or moderate in severity. The authors concluded that IDegAsp was safe and well tolerated and provided comparable overall glycemic control to BIAsp 30. IDegAsp was associated with a significantly lower FPG and a significantly lower rate of hypoglycemia than BIAsp 30.

\section{Phase III trials}

A study has compared the efficacy and safety of IDeg to IGlar. ${ }^{32,33}$ Both insulins were administered once daily as basal/bolus treatment in combination with mealtime IAsp \pm metformin \pm pioglitazone. This 1 -year open-label 
(different pen devices), treat-to-target trial consisted of 992 patients (mean age $=58.9$ years, mean diabetes duration $=13.5$ years, mean $\mathrm{HbA}_{1 \mathrm{c}}=8.3 \%$, mean $\mathrm{FPG}=166 \mathrm{mg} / \mathrm{dL}$ ) who sustained $\mathrm{HbA}_{1 \mathrm{c}}$ levels of $7 \%$ to $10 \%$ after a minimum of 3 months of insulin with or without oral anti-diabetic drugs. Subjects were randomized (3:1) to receive either IDeg or IGlar. Basal insulin was titrated to $\mathrm{FPG}<90 \mathrm{mg} / \mathrm{dL}$. More than $80 \%$ of patients in both groups completed the trial. After 1 year, IDeg and IGlar achieved similar glycemic control, with $\mathrm{HbA}_{1 \mathrm{c}}$ having dropped $1.2 \%$ in the IDeg group and $1.3 \%$ in the IGlar group. Estimated treatment difference IDeg-IGlar was $0.08 \%$ (95\% CI: $-0.05-0.21 ; P=\mathrm{NS})$. In both groups, $50 \%$ of subjects achieved $\mathrm{HbA}_{1 \mathrm{c}}<7 \%$ ( $\left.P=\mathrm{NS}\right)$. FPG was reduced by $43 \mathrm{mg} / \mathrm{dL}$ with IDeg and $38 \mathrm{mg} / \mathrm{dL}$ with IGlar $(\mathrm{ETD}=-5.2 \mathrm{mg} / \mathrm{dL}, 95 \% \mathrm{CI}:-11.7-1.1 ; P=\mathrm{NS})$. Rates of nocturnal confirmed hypoglycemia (defined as $<56 \mathrm{mg} / \mathrm{dL}$ or considered severe per ADA definition, occurring between midnight and 05:59 am) were 25\% lower with IDeg compared with IGlar (1.4 vs 1.8 episodes/ patient-year, $\mathrm{ERR}=0.75,95 \% \mathrm{CI}$ : 0.58-0.99; $P=0.0399$ ). Similarly, rates of confirmed hypoglycemia were lower with IDeg than IGlar (11.1 vs 13.6 episodes/patient-year, ERR IDeg/IGlar $=0.82,95 \%$ CI: $0.69-0.99 ; P=0.0359)$. At 1 year, total mean daily insulin doses were $1.46 \mu / \mathrm{kg}$ and $1.42 \mu / \mathrm{kg}$ in the IDeg and IGlar groups respectively, with a basal/bolus split of approximately 50/50 in the two groups. Adverse events were also similar between groups. In conclusion, IDeg given as basal/bolus treatment with IAsp in people with type 2 diabetes improves long-term glycemic control with significantly lower risk for overall and nocturnal hypoglycemia than IGlar.

\section{Flexible dosing of insulin degludec compared to insulin glargine}

A 26-week, open-label noninferiority, treat-to-target study compared IDeg dosed once daily in a flexible regimen with IGlar. ${ }^{18,20,50}$ People with type 2 diabetes (mean age $=56.5$ years, mean $\mathrm{HbA}_{1 \mathrm{c}}=8.4 \%$, mean $\mathrm{FPG}=161 \mathrm{mg} / \mathrm{dL}$, mean duration of diabetes $=10.6$ years, mean BMI $=29.6 \mathrm{~kg} / \mathrm{m}^{2}$ ) were randomized to IDeg dosed once daily in a flexible regimen (IDeg Flex, a compulsory, rotating morning and evening schedule, creating 8-40-hour dosing intervals; $n=229$ ) or IGlar given at the same time each day $(n=230)$. Insulin was added to existing oral anti-diabetic (OAD) therapy (if any) and titrated to FPG $<90 \mathrm{mg} / \mathrm{dL}$.

Some $88 \%$ of participants completed the trial in both groups. At 26 weeks, IDeg Flex and IGlar reduced
$\mathrm{HbA}_{1 \mathrm{c}}$ by 1.28 and 1.26 points, respectively (ETD IDeg Flex-IGlar $=0.04 \%$ points $[95 \% \mathrm{CI}:-0.12-0.20])$, and noninferiority confirmed as the upper 95\% CI limit was $<0.4$. Mean FPG at week 26 was significantly lower for IDegFlex (104 vs $112 \mathrm{mg} / \mathrm{dL}$, ETD = -7.6 mg/dL, 95\% CI: -14.8 - to $-0.4 ; P=0.04)$, while mean daily doses of insulin were similar between groups. Rates of confirmed hypoglycemia ( $\mathrm{PG}<56 \mathrm{mg} / \mathrm{dL}$, or severe) were similar for IDeg Flex and IGlar (3.6 vs 3.5 episodes/patient-year, ERR IDeg Flex-IGlar $=1.03$, 95\% CI: $0.75-1.40 ; P=\mathrm{NS})$, as were rates of nocturnal confirmed hypoglycemia ( 0.6 vs 0.8 episodes/patient-year, ERR $=0.77,95 \% \mathrm{CI}: 0.44-1.35$; $P=$ NS) and rates of adverse events. The authors concluded that by using extreme dosing intervals of 8 to 40 hours, IDeg can be dosed flexibly at any time of day so that injection times can be changed from day to day without compromising glycemic control or safety compared to IGlar dosed at the same time each day.

\section{Flexible dosing of insulin degludec QD compared to insulin degludec QD with evening meal}

A once-daily administration of IDeg in a flexible dosing regimen (IDeg-Flex, $n=229$ ) was compared with IDeg once daily (OD) administered with the evening meal $(n=228) .{ }^{19}$ At 26 weeks, IDeg Flex and IDegOD improved $\mathrm{HbA}_{1 \mathrm{c}}$ by $1.3 \%$ points and $1.1 \%$ points, respectively (ETD IDegFlexIDegOD $=-0.13 \%$ points, 95\% CI: $-0.29-0.03)$. Mean FPG was reduced by $57.6 \mathrm{mg} / \mathrm{dL}$ (IDeg Flex) and by $54 \mathrm{mg} / \mathrm{dL}$ (IDegOD) $(\mathrm{ETD}=-0.9 \mathrm{mg} / \mathrm{dL}, 95 \% \mathrm{CI}:-8.1-6.3)$. Rates of confirmed hypoglycemia were 3.6 episodes/patient-year in both groups $(\mathrm{ERR}=\mathrm{IDeg}$ Flex/IDegOD $=19.8,95 \% \mathrm{CI}$ : 14.2-27.4). The ratio of nocturnal confirmed hypoglycemia was 0.6 episodes/patient-years in both groups $(\mathrm{ERR}=21.2$, 95\% CI: 11.9-38.2). The study concluded that IDeg insulin can be dosed flexibly at any time of day without affecting glycemic control or risk of hypoglycemia.

\section{Safety and tolerability}

Overall rates of adverse events were similar between groups with no treatment-specific pattern or clustering.

\section{Hypoglycemia}

In all of these trials, confirmed hypoglycemia was defined as a value $<56 \mathrm{mg} / \mathrm{dL}(3.1 \mathrm{mmol})$ or classified as "severe" if requiring assistance from another person. ${ }^{18-20,29,32,33,36-38,41,49-51}$ Confirmed nocturnal hypoglycemic episodes were defined as time of onset between 2300 and 0559 hours (inclusive) ) $^{29,32-34}$ 
and not defined. ${ }^{18-20,26,28,41,49,51}$ Hypoglycemic events in clinical studies of type 1 and type 2 diabetes are summarized in Tables 3 and 4, respectively.

In type 1 diabetes, IDeg significantly reduced the incidence of nocturnal hypoglycemic events by $25 \%$ to $58 \%$ compared to IGlar and detemir. . $6,28,29,36,37$ This effect was seen consistently in all of the trials. Except in one trial, the overall incidence of hypoglycemia was comparable to that of IGlar and insulin detemir. ${ }^{29}$ In a small $(n=28)$ double-blind, two-period, crossover trial, the counter-regulatory hormone responses of both IDeg and IGlar were compared in type 1 patients after eliciting a period of hypoglycemia. The induction of hypoglycemia with IDeg resulted in a significantly greater counterregulatory hormone response compared to IGlar, indicating that enhanced counterregulation may contribute to the observed reduced hypoglycemia risk for IDeg compared with IGlar in patients with type 1 diabetes. ${ }^{27,39}$

In the clinical studies that evaluated hypoglycemia in patients with type 2 diabetes, IDeg administered once a day was compared to IGlar, flexible dosing of IDeg, and BIAsp 30. When compared to IGlar, there was no statistically significant difference in the overall incidence of hypoglycemia or nocturnal hypoglycemia by IDeg. However, it is interesting to note that there was a higher mean rate of hypoglycemic episodes reported in the three-dose-per-week IDeg group than in the once-daily groups. ${ }^{34}$ This may be because of the use of larger doses of insulin that had to be given at every injection to cover the weekly insulin requirements (ie, the starting dose for the three-dose-per-week group was double that of the once-daily group dose).

One study with a duration of 52 weeks demonstrated that the rate of overall confirmed hypoglycemia was $18 \%$ lower with IDeg than with IGlar. ${ }^{32,33}$ This study also noted that IDeg resulted in a $25 \%$ lower rate of nocturnal hypoglycemia than IGlar. In all other studies, the incidence of nocturnal hypoglycemia in patients with type 2 diabetes treated with IDeg was similar to those treated with IGlar $^{18-20,50}$ or not reported..$^{34,38}$ When compared to BIAsp 30, IDeg resulted in a $58 \%$ lower incidence of overall confirmed hypoglycemia. ${ }^{41,49}$ There was also no increased risk of hypoglycemia when IDeg was dosed flexibly at any time of the day. ${ }^{19}$

\section{Body weight}

The effect of IDeg on body weight is unclear because change in body weight at end of study was not reported in all trials with type $1^{26}$ and type 2 diabetes. ${ }^{18-20,32,33,41,49}$ Based on the limited information available, it appears that mean body weight remains stable with only small changes observed after treatment with IDeg compared to IGlar. ${ }^{29,34,38}$ On the other hand, a 26-week study found that there was less weight gain in the detemir group compared with the IDegAsp group $(\mathrm{ETD}=1.0 \mathrm{~kg}, 95 \% \mathrm{CI}: 0.38-1.69 ; P=0.0021) .{ }^{36,37}$

\section{Insulin doses}

At the end of study duration, mean total daily insulin doses were similar between IDeg and IGlar groups, divided 50:50 between the basal and bolus components for both groups. ${ }^{18,26,29,32-34,36,37}$ Only one study reported on changes in basal insulin requirements from pre- to post-trial. ${ }^{29}$ Small increases in mean daily basal insulin dose was also observed from pretrial to end of trial for IDeg (A) (from $29 \pm 12$ units to $30 \pm 13$ units) and IGlar (from $23 \pm 11$ units to $26 \pm 13$ units). Another 16-week study found that mean daily insulin doses at the end of trial were $20 \%$ lower for IDegAsp than IGlar $\left(0.38 \pm 0.16\right.$ vs $0.45 \pm 0.2$, respectively). ${ }^{38}$ Two studies did not report on insulin doses used. ${ }^{19,41,49}$

\section{Mitogenic potential}

Native insulin binds with low affinity to the insulin-like growth factor (IGF-I) receptor, a receptor molecule that shares consistent similarities with the insulin receptor but

Table 3 Incidence of hypoglycemia in type I diabetes

\begin{tabular}{|c|c|c|c|c|c|}
\hline \multirow[t]{2}{*}{$\overline{\text { Study }}$} & \multirow[t]{2}{*}{ Weeks } & \multicolumn{2}{|c|}{ Confirmed hypoglycemia $<56 \mathrm{mg} / \mathrm{dL}(3.0 \mathrm{mmol} / \mathrm{L})$} & \multicolumn{2}{|c|}{ Nocturnal hypoglycemia" } \\
\hline & & Events/patient-year & vs IGlar (ERR (95\% CI)) & Events/patient-year & vs IGlar (ERR (95\% CI)) \\
\hline \multirow[t]{2}{*}{ Birkeland et $a^{\S, 29}$} & 16 & $47.9,59.5,66.2$ & $\operatorname{IDeg}(A):-28 \%(0.72(0.52-1.00))^{\ddagger}$ & $5.1,8.8,12.3$ & $-58 \%(0.42(0.25-0.69))^{\ddagger}$ \\
\hline & & IDeg (A), IDeg (B), IGlar & IDeg (B): $-10 \%(0.90(0.65-1.24))$ & IDeg (A), IDeg (B), IGlar & $-29 \%(0.7 I(0.44-1.16))$ \\
\hline \multirow{3}{*}{$\begin{array}{l}\text { Russell-Jones et al, } \\
\text { Heller et a }{ }^{26,28}\end{array}$} & 52 & 42.5 vs 40.2 & No Change (I.07 (0.89-I.28)) & 4.4 vs 5.9 & $-25 \%(0.75(0.59-0.96))^{\ddagger}$ \\
\hline & & IDeg vs IGlar & & & \\
\hline & & & vs insulin dete & & \\
\hline \multirow[t]{2}{*}{ Hirsch et $\mathrm{al}^{ \pm, 36,37}$} & 26 & 39 vs 44 & $0.9(0.76-1.09)$ & 3.7 vs 5.7 & $-37 \%(0.63(0.49-0.81))^{\ddagger}$ \\
\hline & & IDegAsp vs detemir & & & \\
\hline
\end{tabular}

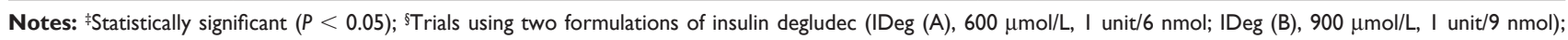
${ }^{ \pm}$IDegAsp (IDeg 70\%; IAsp 30\%); ERR, estimated rate ratio; IGlar, insulin glargine; "Nocturnal hypoglycemic episodes was defined as confirmed hypoglycemia < 56 mg/dL occurring between 2300 and 0559 hours (inclusive) ${ }^{29,36,37}$ and not defined in the following studies. ${ }^{26,28}$ 
Table 4 Incidence of hypoglycemia in type 2 diabetes

\begin{tabular}{|c|c|c|c|c|c|}
\hline \multirow[t]{2}{*}{ Study } & \multirow[t]{2}{*}{ Weeks } & \multicolumn{2}{|c|}{ Confirmed hypoglycemia $<56 \mathrm{mg} / \mathrm{dL}(3.0 \mathrm{mmol} / \mathrm{L})$} & \multicolumn{2}{|c|}{ Nocturnal hypoglycemia" } \\
\hline & & Events/patient-year & vs IGlar (ERR (95\% Cl)) & Events/patient-year & vs IGlar (ERR (95\% CI)) \\
\hline \multirow[t]{3}{*}{ Zinman et al ${ }^{34}$} & 16 & $41,10,15,20 \pi$ & IDeg 3TW: I.I7 (0.46-2.96) & $4,2,1,0$ & Not reported \\
\hline & & & IDegOD (A): $0.44(0.15-1.28)$ & & \\
\hline & & & IDegOD (B): 0.54 (0.19-I.5I) & & \\
\hline \multirow[t]{2}{*}{ Heise et $\mathrm{a}^{38}$} & 16 & $1.2,2.4,0.7^{ \pm}$ & Not reported & Not reported & Not reported \\
\hline & & IDegAsp vs AF vs IGar & & & \\
\hline Garber et al, & 52 & II.I vs 13.6 & $-18 \%(0.82(0.69-0.99))^{\ddagger}$ & I. 4 vs 1.8 & $-25 \%(0.75(0.58-0.99))^{\ddagger}$ \\
\hline Hollander et a ${ }^{32,33}$ & & IDeg vs IGlar & & IDeg vs IGlar & \\
\hline Meneghini et al, & 26 & 3.6 vs 3.5 & $\mathrm{I} .03(0.75-\mathrm{I} .40)$ & 0.6 vs 0.8 & $0.77(0.44-1.35)$ \\
\hline Atkin et al, & & IDegFlex* vs IGlar & & (IDegFlex vs IGlar) & \\
\hline Bain et al $\left.\right|^{18,20,50}$ & & & & & \\
\hline \multirow[t]{4}{*}{ Birkeland et al ${ }^{19}$} & 26 & 3.6 (both groups) & $1.10(0.79-1.52)$ & 0.6 (both groups) & $1.18(0.66-2.12)$ \\
\hline & & IDegFlex* vs IDegOD & & IDegFlex vs IDeg QD & \\
\hline & & & vs BIAsp 30 (biphasic insulin & & \\
\hline & & & aspart 30) (ERR (95\% CI)) & & \\
\hline \multirow[t]{2}{*}{ Vaag et $\mathrm{al}^{41,49,51}$} & 16 & 2.9 vs 7.3 & $-58 \%(0.42(0.23-0.75))^{\ddagger}$ & Not reported & Not reported \\
\hline & & IDegAsp vs BIAsp 30 & & & \\
\hline
\end{tabular}

Notes: गIDeg three times a week (3TW) vs IDeg (A) $(600 \mathrm{nmol} / \mathrm{mL}$ formulation) once daily vs IDeg (B) ( $900 \mathrm{nmol} / \mathrm{mL}$ formulation) once daily vs IGlar (insulin glargine) once daily; ${ }^{ \pm}$IDegAsp is a soluble co-formulation of IDeg (70\%) and insulin aspart (IAsp, 30\%); AF = alternative formulation 55\% IDeg and 45\% IAsp; ${ }^{*} I D e g$ Flex = administered on flexible schedule (alternating between morning and evening creating an 8-40 hour interval between basal insulin doses); ${ }^{*}$ IDeg Asp $=$ IDeg (70\%) and insulin aspart (IAsp 30\%) versus BIAsp 30 = Biphasic insulin aspart 30; †Statistically significant; "nocturnal hypoglycemic episodes was defined as confirmed hypoglycemia < 56 mg/dl occurring between 2300 and 0559 hours (inclusive) ) $^{32-34,38}$ and not defined in the following studies. ${ }^{18-20,41,48-50}$

that has more marked mitogenic and antiapoptotic effects..$^{53}$ The use of structurally modified insulin analogue molecules may lead to different chemical interactions with the binding sites of the receptor molecule (the insulin receptor isoforms [A and B] and the IGF-1 receptor [IGF-IR]).

In vitro studies indicate that the long-acting analogs IGlar and detemir stimulate mitogenic pathways more actively than native insulin via both the IR isoforms and IGF-IR. Insulin analogues display IGF-I-like mitogenic and antiapoptotic activities in cultured cancer cells. ${ }^{54}$ Detemir has a relatively low affinity for the insulin receptor compared to human insulin, and has been shown to preserve the relative affinity ratio for insulin receptors:IGF-1 receptors and the insulin receptor dissociation rate seen for natural human insulin. As a result, there are fewer concerns about increased mitogenicity with insulin detemir. ${ }^{55,56}$

However, in vitro studies of IGlar demonstrate that glargine binds preferentially to insulin-like growth factor-1 (IGF-1) receptors rather than to insulin receptors. This may create a mitogenic potential, especially with long-term use. ${ }^{55,57}$ In animal studies, glargine did not promote tumor growth despite administration at supraphysiological concentrations (nanomolar/micromolar) that are unlikely to be observed in clinical practice as the doses needed to produce these concentrations are liable to lead to hypoglycemia. ${ }^{55}$ Furthermore, glargine in vivo is rapidly transformed into its metabolites, the metabolic and mitogenic characteristics of which have been shown to be broadly equal to those of human insulin. Thus, the suggestion of increased relative mitogenic potency of IGlar seen in some cell lines does not appear to carry over to the in vivo situation in animals and humans. ${ }^{58,59}$ In contrast, epidemiological studies published in 2009 suggested an increased risk of cancer associated with IGlar. ${ }^{60-63}$ At the current time, the US Food and Drug Administration (FDA) has determined that the evidence presented in these studies is inconclusive due to methodological limitations. The FDA is working with the manufacturer of Lantus and the US Department of Veterans Affairs to further evaluate the long-term risk of cancer and IGlar. ${ }^{64}$

Therefore, newly developed insulin should not display increased affinity to the insulin-like growth factor receptor, increased "on" time to the insulin receptor, or other potential mitogenic signals in preclinical and clinical testing. ${ }^{65}$ The in vitro mitogenicity has been investigated and IDeg was found to have a low IGF-1 receptor binding affinity and a low mitogenic/metabolic potency ratio. ${ }^{66,67}$ The clinical relevance of this finding has yet to be confirmed.

\section{Conclusion}

IDeg demonstrates potential use as an ultralong-acting basal insulin analogue with a smooth time-action profile of more than 42 hours. ${ }^{16}$ This unique characteristic allows a more flexible once daily dosing regimen within 8 to 40 hours of administration, thus allowing injection times to be changed from day to day without compromising glycemic control or 
safety. ${ }^{18-20}$ In a proof-of-concept trial, IDeg was evaluated for potential use in a thrice-weekly dosing schedule in insulinnaïve subjects with type 2 diabetes. This trial demonstrated that IDeg administered three times a week provides equivalent glycemic control but with a higher rate of hypoglycemic episodes compared to the once daily IDeg and IGlar groups. ${ }^{34}$ The clinical significance of this dosing regimen remains unknown, as a dosing schedule of every 2 to 3 days may affect adherence and short-term dose adjustments for activity. ${ }^{68}$

In published clinical trials, IDeg has been studied in more than 3000 subjects with type 1 or type 2 diabetes (Tables 1 and 2). There were no reported differences at the end of study between IDeg and its comparators in the reduction of the primary efficacy end-point of hemoglobin A1c in subjects with type 1 and type 2 diabetes. Reductions in mean FPG concentrations were also much the same across all the treatment groups in patients with type 1 diabetes. However, in studies of type 2 diabetes, mean FPG was significantly reduced with flexible dosing of IDeg compared to IGlar ${ }^{18,20}$ and BIAsp 30. ${ }^{41,49}$

IDeg unequivocally demonstrated a significant reduction in nocturnal hypoglycemia compared to IGlar and detemir only in type 1 diabetes (Table 3). Overall, the incidence of hypoglycemic episodes was not remarkably different between IDeg and its comparators in both type 1 and 2 clinical trials. However, in type 2 diabetes, IDeg reduced the incidence of hypoglycemia by $18 \%$ and $58 \%$ compared to IGlar and BIAsp 30 , respectively. ${ }^{32,33,41,49,51}$ Only one trial reported results on health-related quality of life, but this only showed improved mental well-being with IDeg compared to IGlar. ${ }^{48}$

Limitations of the available studies include their open-label design, relatively short duration, and often inadequate sample sizes. Most of the studies were not available in full but were presented as abstracts in conference proceedings. More information will become available in the near future with the completion or near completion of some Phase III clinical trials. It was not possible to draw conclusions on quality of life, economic considerations, dosage and administration, or mortality. The place of IDeg in routine clinical practice remains to be determined.

\section{Disclosure}

The authors report no conflicts of interest in this work.

\section{References}

1. Kurtzhals P. How to achieve a predictable basal insulin? Diabetes Metab. 2005;31(4 Pt 2):4S25-24S33.

2. Rosenstock J, Dailey G, Massi-Benedetti M, Fritsche A, Lin Z, Salzman A. Reduced hypoglycemia risk with insulin glargine: a metaanalysis comparing insulin glargine with human NPH insulin in type 2 diabetes. Diabetes Care. 2005;28(4):950-955.
3. Haak T, Tiengo A, Draeger E, Suntum M, Waldhäusl W. Lower within subject variability of fasting blood glucose and reduced weight gain with insulin detemir compared to NPH insulin in patients with type 2 diabetes. Diabetes Obes Metab. 2005;7(1):56-64.

4. De Leeuw I, Vague P, Selam JL, et al. Insulin detemir used in basal bolus therapy in people with type 1 diabetes is associated with a lower risk of nocturnal hypoglycaemia and less weight gain over 12 months in comparison to NPH insulin. Diabetes Obes Metab. 2005;7(1):73-82.

5. Vague P, Selam JL, Skeie S, et al. Insulin detemir is associated with more predictable glycemic control and reduced risk of hypoglycemia than NPH insulin in patients with type 1 diabetes on a basal-bolus regimen with premeal insulin aspart. Diabetes Care. 2003;26(3):590-596.

6. Ratner RE, Hirsch IB, Neifing JL, Garg SK, Mecca TE, Wilson CA. Less hypoglycemia with insulin glargine in intensive insulin therapy for type 1 diabetes. US Study Group of Insulin Glargine in Type 1 Diabetes. Diabetes Care. 2000;23(5):639-643.

7. Yki-Järvinen H, Dressler A, Ziemen M, HOE 901/300s Study Group. Less nocturnal hypoglycemia and better post-dinner glucose control with bedtime insulin glargine compared with bedtime NPH insulin during insulin combination therapy in type 2 diabetes. HOE 901/3002 study group. Diabetes Care. 2000;23(8):1130-1136.

8. Davies MJ, Derezinski T, Pedersen CB, Clauson P. Reduced weight gain with insulin detemir compared to NPH insulin is not explained by a reduction in hypoglycemia. Diabetes Technol Ther. 2008;10(4):273-277.

9. Raslová K, Tamer SC, Clauson P, Karl D. Insulin detemir results in less weight gain than NPH insulin when used in basal-bolus therapy for type 2 diabetes mellitus, and this advantage increases with baseline body mass index. Clin Drug Investig. 2007;27(4):279-285.

10. Hollander P, Cooper J, Bregnhoj J, Pederson CB. A 52-week, multinational, open-label, parallel-group, noninferiority, treat-to-target trial comparing insulin detemir with insulin glargine in a basal-bolus regimen with mealtime insulin aspart in patients with type 2 diabetes. Clin Ther. 2008;30(11):1976-1987.

11. Rosenstock J, Davies M, Home PD, Larsen J, Koenen C, Schernthaner G. A randomized, 52-week, treat-to-target trial comparing insulin detemir with insulin glargine when administered as add-on to glucose-lowering drugs in insulin naïve people with type 2 diabetes. Diabetologia. 2008;51(3):408-416.

12. Raskin P, Gylvin T, Weng W, Chaykin L. Comparison of insulin detemir and insulin glargine using a basal-bolus regimen in a randomized, controlled clinical study in patients with type 2 diabetes. Diabetes Metab Res Rev. 2009;25(6):542-548.

13. Blonde L, Merilainen M, Karwe V, Raskin P; TITRATE Study Group. Patient-directed titration for achieving glycaemic goals using a oncedaily basal insulin analogue: an assessment of two different fasting plasma glucose targets - the TITRATE study. Diabetes Obes Metab. 2009; 11(6):623-631.

14. Porcellati F, Bolli GB, Fanelli CG. Pharmacokinetics and pharmacodynamics of basal insulins. Diabetes Technol Ther. 2011; 13(Suppl 1):S15-S24.

15. Swinnen SG, Simon AC, Holleman F, Hoekstra JB, Devries JH. Insulin detemir versus insulin glargine for type 2 diabetes mellitus. Cochrane Database Syst Rev. 2011;7:CD006383.

16. Kurtzhals P, Heise T, Strauss HM, et al. Multi-hexamer formation is the underlying mechanism behind the ultra-long glucose-lowering effect of insulin degludec. Paper presented at: American Diabetes Association (ADA) 71st Scientific Session; Jun 2011; San Diego, CA, USA.

17. Mathieu C, Fulcher G, Rao PV, et al. Insulin degludec, a new generation ultra-long acting insulin, used once daily or 3-times weekly in people with type 2 diabetes: Comparison to insulin glargine. Diabetologia. 2010;53(Suppl 1):S8.

18. Meneghini L, Atkin SL, Bain S, et al. Flexible once-daily dosing of insulin degludec does not compromise glycemic control or safety compared to insulin glargine given once daily at the same time each day in people with type 2 diabetes. Paper presented at: American Diabetes Association (ADA) 71st Scientific Session; Jun 2011; San Diego, CA, USA. 
19. Birkeland KI, Raz I, Gough S, et al. Insulin degludec in a flexible daily dosing regimen provides similar glycaemic control without increasing rates of hypoglycaemia compared to dosing the same time daily in type 2 diabetes. Paper presented at: 47th European Association for the Study of Diabetes (EASD) Annual Meeting; Sep 2011; Lisbon, Portugal.

20. Atkin SL, Bain SC, Gough S, et al. Insulin degludec does not compromise efficacy or safety when given in a flexible once-daily dosing regimen compared to insulin glargine once daily at the same time each day in type 2 diabetes. Paper presented at: 47th European Association for the Study of Diabetes (EASD) Annual Meeting; Sep 2011; Lisbon, Portugal.

21. Home PD, Meneghini L, Ratner RE, et al. A comparison of quality of life measured with the SF-36 for insulin degludec and insulin glargine in people with type 1 diabetes. Paper presented at: 47th European Association for the Study of Diabetes (EASD) Annual Meeting; Sep 2011; Lisbon, Portugal.

22. Jonassen I, Havelund S, Ribel U, et al. Insulin degludec is a new generation ultra-long acting basal insulin with a unique mechanism of protraction based on multi-hexamer formation. Diabetes. 2010;59(Suppl 1):A11.

23. Jonassen I, Havelund S, Ribel U, et al. Insulin degludec: Multi-hexamer formation is the underlying basis for this new generation ultra-long acting basal insulin. Diabetologia. 2010;53(Suppl 1):S388.

24. Meneghini LF, Miranda-Palma B. Insulin degludec: A novel ultralong-acting basal insulin for use in type 1 and 2 diabetes. Expert Rev Endocrinol Metab. 2012;7(1):9-14.

25. Nosek L, Heise T, Bøttcher SG, Hastrup H, Haahr H. Ultra-long-acting insulin degludec has a flat and stable glucose-lowering effect. Paper presented at: American Diabetes Association (ADA) 71st Scientific Session; Jun 2011; San Diego, CA, USA.

26. Russell-Jones DL, Francisco AO, Pei H, Heller SR. Basal-bolus therapy with insulin degludec improves long-term glycaemic control with less nocturnal hypoglycaemia compared with insulin glargine in type 1 diabetes: Results of a 1-year trial. Paper presented at: 47th European Association for the Study of Diabetes Meeting (EASD) Annual Meeting; Sept 2011; Lisbon, Portugal.

27. Pieber T, Korsatko S, Koumlhler G, et al. Response to induced hypoglycemia in type 1 diabetes: Insulin degludec elicits an enhanced counterregulatory hormone response compared to insulin glargine. Paper presented at: American Diabetes Association (ADA) 71st Scientific Session; June 2011; San Diego, CA.

28. Heller S, Francisco AO, Pei H, Russell-Jones D. Insulin degludec improves long-term glycemic control with less nocturnal hypoglycemia compared with insulin glargine: 1-year results from a randomized basalbolus trial in type 1 diabetes. Paper presented at: American Diabetes Association 71st Scientific Sessions; Jun 2011; San Diego, CA.

29. Birkeland KI, Home PD, Wendisch U, et al. Insulin degludec in type 1 diabetes: a randomized controlled trial of a new-generation ultra-long-acting insulin compared with insulin glargine. Diabetes Care. 2011;34(3):661-665.

30. Meneghini LF, Home PD, Wendisch U, et al. Insulin degludec, a new generation ultra-long acting insulin, in a mealtime + basal regimen in people with type 1 diabetes: Comparison to insulin glargine. Diabetologia. 2010;53(Suppl 1):S381.

31. Cuddihy R, Tack CJ, Heise T, et al. Once-daily use of a new generation ultra-long acting basal insulin with a bolus boost in insulin-naive people with type 2 diabetes: Comparison with insulin glargine. Diabetologia. 2010;53(Suppl 1):S389.

32. Hollander PA, King AB, Francisco AO, Endahl L, Garber A. Basal-bolus therapy with insulin degludec improves long-term glycaemic control with fewer nocturnal hypoglycaemic events compared with insulin glargine in people with type 2 diabetes. Paper presented at: 47th European Association for the Study of Diabetes (EASD) Annual Meeting; Sep 2011; Lisbon, Portugal.

33. Garber AJ, King AB, Francisco AO, Endahl L, Hollander PA. Insulin degludec improves long-term glycemic control with less nocturnal hypoglycemia compared with insulin glargine: 1-year results from a randomized basal-bolus trial in people with type 2 diabetes. Paper presented at: American Diabetes Association (ADA) 71st Scientific Sessions; Jun 2011; San Diego, CA.
34. Zinman B, Fulcher G, Rao PV, et al. Insulin degludec, an ultralong-acting basal insulin, once a day or three times a week versus insulin glargine once a day in patients with type 2 diabetes: a 16-week, randomised, open-label, phase 2 trial. Lancet. 2011;377(9769): 924-931.

35. Heise T, Hermanski L, Nosek I, et al. Insulin degludec: Less pharmacodynamic variability than insulin glargine under steady state conditions. Diabetologia. 2010;53(Suppl 1):S387.

36. Hirsch I, Franek E, Courrèges JP, Mersebach H, Dykiel P, Bode BW. IDegAsp, a soluble insulin combination of ultra-long-acting insulin degludec and insulin aspart, used once daily in basal-bolus treatment with insulin aspart in type 1 diabetes. Paper presented at: 47 th European Association for the Study of Diabetes (EASD) Annual Meeting; Sep 2011; Lisbon, Portugal.

37. Hirsch IB, Franek E, Courreges J, Mersebach H, Dykiel P, Bode BW. Efficacy and safety of a new basal insulin with a bolus boost (IDegAsp) used once daily in combination with insulin aspart (IAsp) in people with type 1 diabetes. Paper presented at: American Diabetes Association 71st Scientific Sessions; Jun 2011; San Diego, CA.

38. Heise T, Tack CJ, Cuddihy R, et al. A new-generation ultra-long-acting basal insulin with a bolus boost compared with insulin glargine in insulin-naive people with type 2 diabetes: a randomized, controlled trial. Diabetes Care. 2011;34(3):669-674.

39. Heller SR, Pieber TR, Korsatko S, et al. A higher counter-regulatory hormone response is seen with insulin degludec than insulin glargine in response to induced hypoglycaemia in type 1 diabetes. Paper presented at: 47th European Association for the Study of Diabetes (EASD) Annual Meeting; Sep 2011; Lisbon, Portugal.

40. Jonassen I, Hoeg-Jensen T, Havelund S, Ribel U. Ultra-long acting insulin degludec can be combined with rapid-acting insulin aspart in a soluble co-formulation. J Pept Sci. 2010;16(Suppl 1):32.

41. Vaag A, Leiter LA, Franek E, et al. Use of a new basal insulin with a bolus boost (IDegAsp) in type 2 diabetes: Comparison with biphasic insulin aspart 30 (BIAsp 30). Paper presented at: American Diabetes Association (ADA) 71st Scientific Session; Jun 2011; San Diego, CA.

42. Korsatko S, Deller S, Zahiragic S, et al. Ultra-long-acting insulin degludec: Bio-equivalence and similar pharmacodynamics shown for two different formulations (U100 and U200). Paper presented at: 47th European Association for the Study of Diabetes Meeting (EASD) Annual Meeting; Sep 2011; Lisbon, Portugal.

43. Heise T, Hövelmann U, Nosek L, Bøttcher SG, Granhall C, Haahr H. Insulin degludec has a two-fold longer half-life and a more consistent pharmacokinetic profile than insulin glargine. Paper presented at: American Diabetes Association 71st Scientific Sessions; Jun 2011; San Diego, CA.

44. Heise T, Hermanski L, Nosek L, Feldmann A, Rasmussen S, Haahr H. The pharmacodynamic variability of insulin degludec is consistently lower than insulin glargine over 24 hours at steady state. Paper presented at: American Diabetes Association 71st Scientific Sessions; June 2011; San Diego, CA.

45. Danne T, Biester T, Blaesig S, et al. The pharmacokinetic properties of insulin degludec in children and adolescents compared with adults with type 1 diabetes after single-dose administration. Pediatric Diabetes. 2011;12(Suppl 15):35-36.

46. ClinicalTrials.gov. Investigating the Pharmacokinetic Properties of NN1250 in Healthy Chinese Subjects. [updated 2011 November 28]. Available at: http://clinicaltrials.gov/show/NCT01437592. Accessed December 30, 2011.

47. Meneghini LF, Home PD, Wendisch U, et al. Insulin degludec, a new generation ultra-long acting insulin, in a mealtime plus basal regimen in people with type 1 diabetes: Comparison to insulin glargine. Diabetes. 2010;59(Suppl 1):A152.

48. Home PD, Meneghini L, Wendisch U, et al. Improved health status with insulin degludec compared with insulin glargine in people with type 1 diabetes. Diabet Med. 2011. doi:10.1111/j.1464-5491. 2011.03547.x 
49. Vaag LA, Leiter E, Franek J, et al. IDegAsp, a soluble insulin combination of ultra-long acting insulin degludec and insulin aspart, in type 2 diabetes: Comparison with biphasic insulin aspart 30. Paper presented at: 47th European Association for the Study of Diabetes Meeting (EASD) Annual Meeting; Sep 2011; Lisbon, Portugal.

50. Bain S, Atkin S, Gough S, et al. Flexible once-daily dosing of insulin degludec is as efficacious and safe as insulin glargine given the same time each day in type 2 diabetes. Paper presented at: World Diabetes Congress (International Diabetes Federation); Dec 2011, Dubai.

51. Niskanen L, Leiter LA, Franek E, et al. IDegAsp, a soluble insulin combination of insulin degludec and insulin aspart, in type 2 diabetes: Comparison to biphasic insulin aspart 30. Paper presented at: World Diabetes Congress (International Diabetes Federation); Dec 2011, Dubai.

52. Clinical Trials at Novo Nordisk [homepage on the Internet]. Available at: HYPERLINK http://www.novonordisk-trials.com/t_blank www. novonordisk-trials.com. Accessed January 14, 2012

53. Vigneri R, Squatrito S, Sciacca L. Insulin and its analogs: actions via insulin and IGF receptors. Acta Diabetol. 2010;47(4):271-278.

54. Weinstein D, Simon M, Yehezkel E, Laron Z, Werner H. Insulin analogues display IGF-I-like mitogenic and anti-apoptotic activities in cultured cancer cells. Diabetes Metab Res Rev. 2009;25(1):41-49.

55. Kurtzhals P, Schäffer L, Sørensen A, et al. Correlations of receptor binding and metabolic and mitogenic potencies of insulin analogs designed for clinical use. Diabetes. 2000;49(6):999-1005.

56. Dejgaard A, Lynggaard H, Råstam J, Krogsgaard Thomsen M. No evidence of increased risk of malignancies in patients with diabetes treated with insulin detemir: a meta-analysis. Diabetologia. 2009;52(12):2507-2512.

57. Kellerer M, Häring H. Insulin analogues: impact of cell model characteristics on results and conclusions regarding mitogenic properties. Exp Clinl Endocrinol Diabetes. 2001;109(1):63-64.

58. Wang F, Carabino JM, Vergara CM. Insulin glargine: a systematic review of a long-acting insulin analogue. Clin Ther. 2003;25(6): 1541-1577; discussion 1539-1540.
59. Ciaraldi TP, Sasaoka T. Review on the in vitro interaction of insulin glargine with the insulin/insulin-like growth factor system: potential implications for metabolic and mitogenic activities. Horm Metab Res. 2011;43(1):1-10.

60. Hemkens LG, Grouven U, Bender R, et al. Risk of malignancies in patients with diabetes treated with human insulin or insulin analogues: a cohort study. Diabetologia. 2009;52(9):1732-1744.

61. Colhoun HM, SDRN Epidemiology Group. Use of insulin glargine and cancer incidence in Scotland: a study from the Scottish Diabetes Research Network Epidemiology Group. Diabetologia. 2009;52(9):1755-1765.

62. Jonasson JM, Ljung R, Talbäck M, Haglund B, Gudbjörnsdòttir S, Steineck G. Insulin glargine use and short-term incidence of malignancies - a population-based follow-up study in Sweden. Diabetologia. 2009;52(9):1745-1754.

63. Mannucci E, Monami M, Balzi D, et al. Doses of insulin and its analogues and cancer occurrence in insulin-treated type 2 diabetic patients. Diabetes Care. 2010;33(9):1997-2003.

64. US Food and Drug Administration. FDA Drug Safety Communication: Update to ongoing safety review of Lantus (insulin glargine) and possible risk of cancer. [updated 2011 January 20]. Available at: http:// www.fda.gov/Drugs/DrugSafety/ucm239376.htm. Accessed March 17, 2012 .

65. Simon AC, DeVries JH. The future of basal insulin supplementation. Diabetes Technol Ther. 2011;13(Suppl 1):S103-S108.

66. Nishimura E, Sorensen AR, Hansen BF, et al. Insulin degludec: A new ultra-long, basal insulin designed to maintain full metabolic effect while minimizing mitogenic potential. Diabetologia. 2010; 53 (Suppl 1):S388.

67. Nishimura E, Sorensen A, Hansen BF, et al. Insulin degludec is a new generation ultra-long acting basal insulin designed to maintain full metabolic effect while minimizing mitogenic potential. Diabetes. 2010;59(Suppl 1):A375.

68. Ahrén B, Burke B. Using albumin to improve the therapeutic properties of diabetes treatments. Diabetes Obes Metab. 2012;14(2):121-129.

\section{Publish your work in this journal}

Diabetes, Metabolic Syndrome and Obesity: Targets and Therapy is an international, peer-reviewed open-access journal committed to the rapid publication of the latest laboratory and clinical findings in the fields of diabetes, metabolic syndrome and obesity research. Original research, review, case reports, hypothesis formation, expert opinion and commentaries are all considered for publication. The manuscript management system is completely online and includes a very quick and fair peer-review system, which is all easy to use. Visit http://www.dovepress.com/testimonials.php to read real quotes from published authors. 